\title{
Taking Away Excuses to Quit: The Role of Supports in Completion and Learning in Online Professional Development for Teachers
}

\author{
Sara Rutherford-Quach \\ SRI International \\ Karen D. Thompson \\ College of Education, Oregon State University \\ Claudia Rodriguez-Mojica \\ Department of Education, Santa Clara University \\ Diego Román \\ Department of Curriculum \& Instruction, School of Education, University of Wisconsin-Madison
}

\begin{abstract}
Online courses, particularly in the massive open online course (MOOC) format, have been lauded for their potential to democratize access to educational opportunities but criticized for their markedly low completion rates. Yet educators continue to enroll in online courses, including MOOCs, in high numbers. For teachers at under-resourced schools, free online courses may be the only professional development option. It thus remains important to understand whether online courses, in their various formats, can serve as vehicles to support teacher learning and whether this can happen on a large-scale. Extending prior research that explores the relationship between contextual factors, engagement, and learning in online settings, this mixed-method study examines outcomes in a MOOC designed for teachers of English learners (ELs). In particular, the study identifies and examines structural and social supports that were available to some course participants (release time, stipends, participating with colleagues, and having a facilitator who convened face-to-face meetings) and investigates whether these local conditions were significantly related to completion and learning. Findings indicate that participants who received more supports were significantly more likely to complete the course. While participants, on average, showed evidence of learning, participants receiving supports did not show evidence of learning more than other participants. This is potentially due to omitted variable bias because participants who completed the course without supports may differ from participants who completed the course with supports in important, unaccounted for ways. This study extends prior research about how learning environments impact online learning experiences and suggests that structural and social supports may be useful in facilitating MOOC completion.
\end{abstract}

Keywords: MOOCs, teacher professional development, classroom discourse

Rutherford-Quach, S., Thompson, K.D., Rodriguez-Mojica, C., \& Román, D. (2021). Taking away excuses to quit: The role of supports in completion and learning in online professional development for teachers. Online Learning, 25(2), 140-170. https://doi.org/10.24059/olj.v25i2.1586 


\section{Taking Away Excuses to Quit: The Role of Supports in Completion and Learning within Online Professional Development}

Online courses, particularly in the massive open online course (MOOC) format, initially gained positive attention for the potential to democratize access to educational opportunities (Jona $\&$ Naidu, 2014). In addition, MOOCs held promise as a professional development venue for those in a wide range of professions, including K-12 teachers (Laurillard, 2016). The reputation of MOOCs began to fade, however, with reports of low completion rates. (Perna et al., 2014; Ruby, Boruch, Wang, Scull, Ahmad \& Evans, 2014). Education researchers further criticized MOOCs, asserting that most were not grounded in sound learning theory nor aligned with established principles of effective online professional development (Elliott, 2017; Pollard, Minor, \& Swanson, 2014).

K-12 teachers have continued to enroll in online courses, including MOOCs, in large numbers despite these criticisms, and MOOCs have experienced a resurgence in recent years (Ho et al., 2014; Lohr, 2020; Parsons et al., 2019). For teachers at under-resourced or isolated schools and educating under-served populations such as English learners (ELs), free online courses may be their only professional development option (Rutherford-Quach, Kuo, \& Hsieh, 2018; Laurillard, 2016). It thus remains important to understand if and how MOOCs can serve as vehicles for supporting teacher learning and whether this can happen on a large-scale.

Prior research has explored how a variety of contextual factors impact engagement and learning in online courses (e.g., Evans, Baker, \& Dee, 2016; Gašević, Dawson, Rogers, \& Gašević, 2016; Joksimović et al., 2018). In this study, we analyzed engagement and learning in a MOOC designed for teachers of ELs. Some participants in this MOOC had access to structural supports provided by their school district-release time and/or stipends-intended to make MOOC participation more feasible. Some had access to social supports - participating in the MOOC with colleagues and/or having a facilitator who convened face-to-face meetings. We extend prior work on the role of contextual factors in online learning by exploring the relationship between these local supports and participants' completion and learning.

Drawing on both quantitative and qualitative data - including pre- and post-course surveys, assignment submissions, course completion information, and interviews with district administrators who designed the supports for participants-we explored the following two research questions:

1. What is the relationship between structural and social supports provided by districts and teachers' completion of the online professional development?

2. What is the relationship between these supports and evidence of teacher learning in the course?

To answer these questions, we begin by contextualizing our research in the literature. First, we review the existing literature about contextual factors that impact engagement and learning in online education with focus on features of the learning environment (Halverson \& Graham, 2019). Second, we review prior literature about factors that facilitate teachers' participation in professional development. We go on to describe the theoretical framework for our study, which posits that local conditions outside courses, such as access to structural and social supports, impact engagement and learning in online settings. Next, we provide a brief overview of the online professional development course we examined. We then detail the study's methodology. 
Subsequently, we present findings, first addressing the relationship between supports and course completion, and second, exploring the relationship between supports and teacher learning. Finally, we discuss limitations of the study and share implications for research and practice.

\section{Review of Related Literature}

\section{Research about Factors Affecting Engagement and Learning in Online Contexts}

Scholars have argued that there are many parallels between online and face-to-face settings in terms of the relationship between contextual factors, engagement, and learning, though the contextual factors that are relevant in face-to-face and online settings differ (Evans, Baker, \& Dee, 2016; Gašević, Dawson, Rogers, \& Gašević, 2016; Halverson \& Graham, 2019; Joksimović et al., 2018). Specifically, as Joksimović and colleagues (2018) argue in their recent synthesis of MOOC research, contextual factors influence engagement, which in turn influences learning. In studies addressing the role contextual factors play in online learning, researchers have considered factors at the student level-also referred to as internal factors (Gašević, Dawson, Rogers, \& Gašević, 2016) or learner characteristics (Halverson \& Graham, 2019). In addition, researchers have considered factors at the course level — also referred to as instructional conditions (Gašević et al., 2016) or characteristics of the learning experience (Halverson \& Graham, 2019). At the student level, for example, Green, Oswald, and Pomerantz (2015) identified a variety of factors related to MOOC outcomes, including having work experience related to the topic and expressing a higher level of commitment to completing the course at the outset. Meanwhile, at the course level, research has identified a variety of factors related to differences in online learning outcomes. For example, Evans and colleagues (2016) found that students in MOOCs lasting for a longer time period had lower levels of engagement and completion (Evans et al., 2016). In another study of MOOCs, Adamopoulos (2013) found that participants in self-paced courses had lower levels of completion than those in more structured courses. In addition, Adamopoulos (2013) found that participants in courses with peer assessments were significantly more likely to complete the course.

Drawing on Joksimović and colleagues' (2018) framework for the relationship between contextual factors, engagement, and learning, we can consider course format (online, face-to-face, or blended) to be a contextual factor influencing engagement and learning. Several meta-analyses have found positive effects for blended learning on student achievement compared to fully online or face-to-face instruction (Bernard, Borokhovski, Schmid, Tamim, \& Abrami, 2014; Means, Toyama, Murphy, \& Baki, 2013). However, these positive findings may be the result of other factors, such as the increased time participants spent engaging with course materials in blended contexts, rather than a direct result of the blended format itself (Means et al. 2013). Given the breadth of online and blended learning opportunities, there is still much more to understand about the impact of specific contextual factors, particularly features of the learning environment, on outcomes.

Turning to online professional development for teachers specifically, researchers have made theoretical arguments about features of the learning environment that should facilitate engagement and learning in fully online and blended contexts. Following tenets of social constructivism, research has argued that effective online professional development for teachers should be interactive, collaborative, interest-driven, differentiated, ongoing (rather than episodic), and connected to teachers' day-to-day practice (Elliott, 2017). Many of these characteristics 
overlap with characteristics of effective teacher professional development previously identified in face-to-face contexts (Darling-Hammond et al., 2017; Wei et al., 2009). Some research specifically focused on teacher professional development found benefits of blended learning environments compared to online-only environments (Matzat, 2013). Blended learning environments may be better suited to provide effective teacher professional development due to increased opportunities for interaction, collaboration, and reflection (Elliott, 2017; Matzat, 2013; Means et al., 2013), which social constructivist learning theory posits are essential to the learning process (Lave \& Wenger, 1991; Vygotsky 1978). Yet limited research has empirically tested how contextual factors and features of the learning environment impact engagement and learning in online professional development for teachers (Dede, 2009; EdSurge, 2014; Matzat, 2013; Halverson \& Graham, 2019; Parsons et al., 2019; Yurkofsky, Blum-Smith, \& Brennan, 2019).

\section{Research on Factors Impacting Teachers' Decisions to Participate in Professional Development}

Research about contextual factors impacting engagement and learning in online settings is a relatively new area of inquiry. A separate strand of research, however, has examined factors that influence adults' decisions to participate in learning opportunities more generally and teachers' decisions to participate in professional development specifically for over 50 years. The first crucial step in completion and learning in any setting is deciding to participate. Therefore, this line of inquiry is directly related to our research questions about the relationship between structural and social supports and completion and learning in a MOOC for teachers. Research has demonstrated that situational barriers - particularly time constraints and monetary costs - impact adults' decisions to participate in educational opportunities (Bigsby \& Firestone, 2017; Darkenwald \& Valentine, 1985; Hargraves, 1992; Johnstone \& Rivera, 1965; Lohman, 2005). For instance, in a study of secondary school teachers in the Netherlands, Kwakman (2003) found that teachers' assessments of the feasibility of participation were key drivers of their decisions. Similarly, in a study of New Jersey middle school teachers' decisions about whether to participate in professional development, Bigsby and Firestone (2017) concluded, “"[V]oluntary professional development ... should be designed to reduce barriers to participation. The key, but not only, barrier here is time" (p. 90). Another barrier inhibiting teachers' engagement in professional development opportunities is cost or a lack of monetary rewards, which is particularly relevant given teachers' comparatively low salaries (Allegretto \& Mishel, 2019; Lohman, 2000; Lohman, 2005). To diminish these barriers and motivate participation, schools and districts may offer monetary incentives and/or provide dedicated professional development time (Scribner, 1999; Wei et al., 2009).

Research about decisions to participate in professional development has found that social incentives also increase the likelihood of participation. Following sociocultural learning theory, particularly the influential concept of communities of practice (Lave \& Wenger, 1991; Wenger 1998), we would expect that teachers would be more motivated to participate and learn more if they engaged in professional development alongside colleagues. In their study of teachers' decisions about whether to participate in professional development, Bigsby and Firestone (2017) found that the opportunity to collaborate with colleagues was an important reason why teachers participated. Collaborative professional development helped participants get practical advice from their colleagues and support each other through challenging situations (Bigsby \& Firestone, 2017). Similarly, a recent study of a blended community of practice for educators found that participants valued the opportunity to learn and grow alongside their peers, "support[ing] one another in overcoming authentic classroom challenges" (Trust \& Horrocks, 2017, p. 658). Together, these 
studies suggest that both the anticipation and the continued reality of social incentives motivate teachers' participation in professional development.

\section{Theoretical Framework}

Following Joksimović et al's (2018) framework that accounts for interaction between context, engagement, and learning, our study examines the role that particular features of the learning environment play in engagement and learning in blended settings. In contrast to past research, which has focused on the design of online courses per se (e.g., Adamopoulos, 2013; Evans et al., 2016), we examine how local conditions - outside the online course but impacting the learning environment — shape engagement and learning. Specifically, we examine how structural and social supports provided by school districts relate to teachers' engagement and learning within a MOOC. To assess engagement within the course, we focus on course completion. While course completion is only one aspect of engagement, it is a metric that has been widely used to assess this construct (Halverson \& Graham, 2019). To assess learning within the course, we use a variety of self-reported measures of learning, as well as a novel direct measure of learning described in more detail in the Data and Methods section.

The structural supports some districts provided-release time and/or a stipend for participation-may have impacted teachers' initial decisions regarding the feasibility of participation (Kwakman, 2009), thus leading teachers to participate who might not have otherwise, and providing external structures that supported their ongoing engagement. Access to these structural supports may be associated with higher levels of completion and higher levels of learning as well. Simultaneously, the social supports some districts provided - participating in the MOOC with colleagues and/or having a facilitator who convened face-to-face meetings - may have increased social incentives for participation (Bigsby \& Firestone, 2017). Teachers with access to these social supports may have had opportunities for collaboration, dialogue, and social interactions not only in the online course also face-to-face, creating the conditions that, according to social constructivist learning theory, facilitate learning (Askeroth \& Richardson, 2019; Lave \& Wenger, 1991; Vygotsky, 1978; Wenger, 1998). These social incentives may also have supported teachers' completion and learning. Figure 1 provides a visual illustration of how the contextual features of the learning environment we examine may impact engagement and learning. We use italics to indicate the contextual factors we examine in our study. 


\section{Figure 1}

\section{Theoretical Framework}

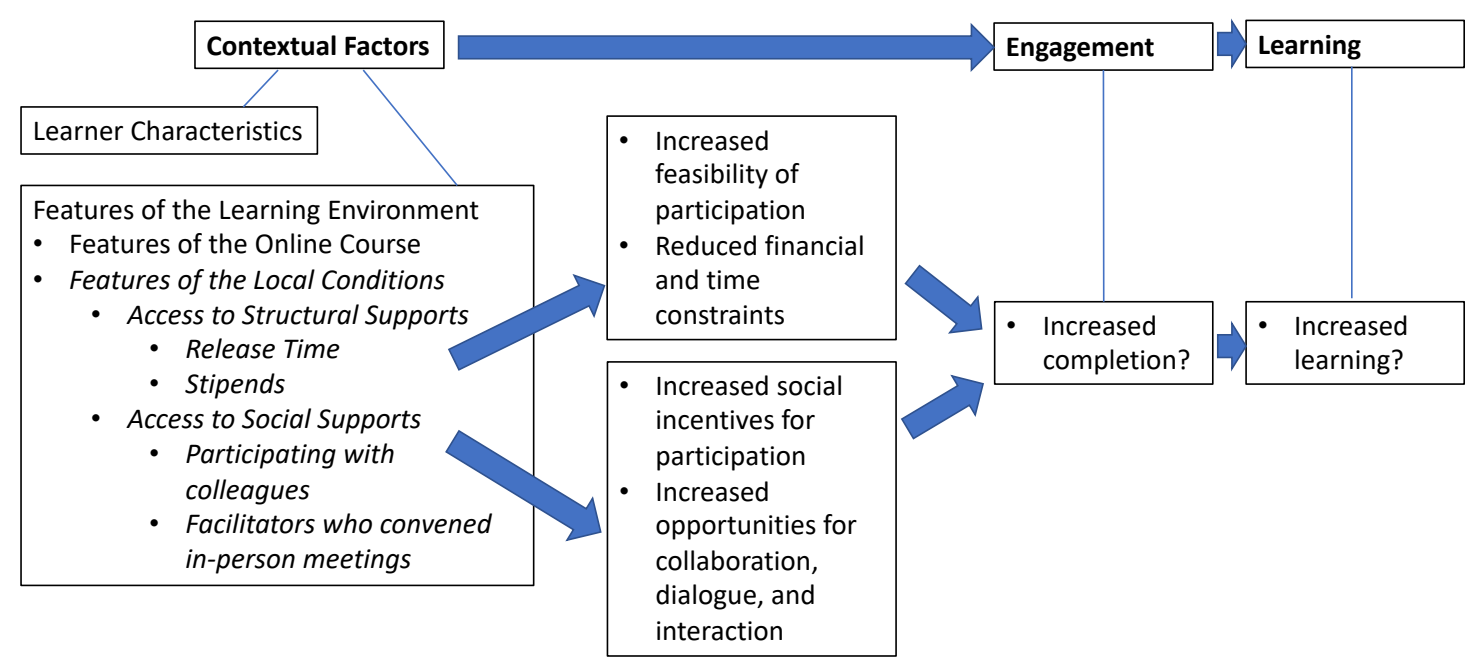

\section{The Online Professional Development Course}

Our findings about course completion and teacher learning are better understood when situated within the context of the online course that is the focus of this study. Oregon State University and Stanford University jointly launched a free online professional development course designed for teachers. This course focused on supporting K-12 students, and particularly students classified as English learners, to engage in argumentation, an analytical and linguistic practice at the heart of college- and career-readiness standards (Stage et al., 2013). The course was conducted via the NovoEd online learning platform, which was chosen due to its collaborative learning focus and functionality. The Oregon Department of Education (ODE) funded the course as an initiative for providing professional development to teachers. The online course drew significant attention from practitioners, with 5,102 educators enrolling. While anyone in the world could participate in the course, ODE also provided grants to select Oregon districts to support teachers' participation.

This provided the opportunity to explore how structural and social supports offered at the local level impact completion and learning in online professional development. On pre- and postcourse surveys, we asked Oregon participants to indicate ways in which their schools or districts were supporting their participation, if any. Participants could indicate whether they were receiving one or more of the following supports: 1) receiving release time to participate in the course activities; 2) receiving a stipend for their course participation; 3) participating in the course with a team of colleagues from their school or district; 4) engaging in the course with the support of a district-provided facilitator; 5) receiving support from their school or district for their course participation in another way; and/or 6) participating in the course without explicit support from their school or district. Therefore, we were able to explore potential differences in completion rates and learning outcomes across participants receiving different types of supports. 
Principles of effective online professional development were addressed in the focal course design by incorporating interaction, collaboration, differentiation, and connections to practice Specifically, participants engaged in: 1) collecting and transcribing language samples of their K12 students $^{3}$ engaging in argumentation in different content areas (e.g., science, language arts); 2) analyzing these language samples using a rubric created in consultation with national experts; 3 ) reviewing the student language samples collected by other participants and providing peer feedback; 4) designing their own lesson plans based on what they learned about their students' argumentation skills; and 5) repeating the cycle of data collection, analysis, peer feedback, and teaching in response to insights. Through these multiple cycles of data collection, analysis, and peer feedback, participants developed understanding of argumentation.

The course had four targeted outcomes for participants:

1. Develop a practical understanding of argumentation, with an emphasis on what this looks like in linguistically diverse classrooms focused on teaching to new standards.

2. Listen more carefully to student argumentation and use a tool (i.e., the Argumentation Analysis Tool [AAT]) to analyze student argumentation, focusing on how students build disciplinary knowledge and language.

3. Learn and implement practical teaching strategies for building students' abilities to engage in argumentation.

4. Collaborate with other educators and build professional relationships that result in an online community focused on improving student argumentation across disciplines and grade levels.

There were four online professional development sessions, and each included readings, videos, and assignments aligned with these learning outcomes. Videos of students in K-12 classrooms engaging in argumentation were a key component of the learning materials for each session. Districts that chose to provide supports for participants determined on their own what these supports would be and how they would function, including how to structure any face-to-face meetings.

\section{Methods}

\section{Subjects}

Subjects in our study consist of Oregon educators enrolled in the online argumentation course. Subjects were grouped by whether or not they reported receiving local support (Table 1). Approximately three-fourths of those enrolled were teachers. The largest group (43\%) taught in the elementary grades. Participants had an average of approximately 15 years professional experience. The overwhelming majority (89\%) worked with ELs. Approximately three-fourths had taken an online course before, while about one-third had taken a previous course on student discourse. Comparing the characteristics of our sample to the general population of U.S. educators, we see many similarities. For example, the average years of teaching experience across U.S. public school educators is 13.7 (U.S. Department of Education, National Center for Education Statistics [NCES], 2016), just slightly below our sample average of 14.7. Similarly, the proportion of educators in our sample who had previously participated in online professional development aligned with a national survey ( $72 \%$ for our sample compared to $77 \%$ in the national survey; Parsons et al., 2019). Unsurprisingly, given that our course was focused on EL education, our 
sample included a higher percentage of teachers who work with ELs compared to the national average (89\% for our sample compared to 56\% nationally; NCES, 2012).

\section{Table 1}

Sample Characteristics among Oregon Educators

\begin{tabular}{lccc}
\hline & $\begin{array}{c}\text { Oregon educators } \\
\text { receiving no supports }\end{array}$ & $\begin{array}{c}\text { Oregon educators } \\
\text { receiving supports }\end{array}$ & All Oregon educators \\
\hline Teacher & $72 \%$ & $76 \%$ & $75 \%$ \\
\hline Grade level & $37 \%$ & & \\
$\quad$ Elementary & $22 \%$ & $45 \%$ & $43 \%$ \\
Middle & $22 \%$ & $21 \%$ & $21 \%$ \\
High & $18 \%^{*}$ & $25 \%$ & $24 \%$ \\
Postsecondary/Other & & $9 \%^{*}$ & $12 \%$ \\
\hline Years of experience & $14 \%$ & & $11 \%$ \\
$1-2$ & $18 \%$ & $9 \%$ & $15 \%$ \\
$3-5$ & $23 \%$ & $13 \%$ & $24 \%$ \\
$6-10$ & $25 \%$ & $25 \%$ & $24 \%$ \\
$11-15$ & $12 \%$ & $24 \%$ & $17 \%$ \\
$16-20$ & $7 \%$ & $19 \%$ & $9 \%$ \\
$>20$ & 15.2 & $10 \%$ & 14.7 \\
\hline Mean years of experience & $85 \%$ & 14.5 & $89 \%$ \\
\hline Work with ELs now & $75 \%$ & $91 \%$ & $72 \%$ \\
\hline Previous online course & $31 \%{ }^{*}$ & $70 \%$ & $38 \%$ \\
\hline Previous course about discourse & $\mathbf{1 3 4}$ & $41 \%{ }^{*}$ & $\mathbf{4 1 4}$ \\
\hline $\mathbf{N}$ & & $\mathbf{2 8 0}$ & \\
\hline
\end{tabular}

Note. $*=p<.05$ when testing the significance of the difference in the specific characteristic for Oregon educators receiving no supports and those receiving supports.

\section{Data Analysis}

We used a variety of data sources and both quantitative and qualitative methods to answer our two main research questions:

1) What is the relationship between structural and social supports provided by districts and teachers' completion of the online professional development?

2) What is the relationship between these supports and evidence of teacher learning in the course?

In the sections that follow, we describe the data sources and analytical procedures undertaken for each of these questions. 


\section{Relationships between Supports and Course Completion}

To address the first research question concerning the relationship between supports and completion, we conducted five analyses. We first constructed variables for the types of supports participants received as reported in the pre-course survey. Next, we constructed variables for course completion using data from the online course platform provider, NovoEd. Specifically, we obtained information about whether participants had submitted each of the three course assignments. Participants who completed these assignments, along with a variety of other tasks, such as completing the pre- and post-course surveys, completing peer evaluations for at least five other participants for each assignment, and completing a fourth collaborative assignment, earned a Statement of Accomplishment from the platform provider. ${ }^{1}$

We then undertook our first analysis by tabulating the types of supports participants received. Next, we calculated overall course completion rates. Prior research has documented a "funnel of participation" in MOOCs, with many people being aware of the course, but a small fraction of these individuals registering, an even smaller fraction engaging with the course content, and then an even smaller fraction completing the course (Clow, 2013). Thus, following other MOOC studies (e.g., Greene et al., 2015), we calculated completion rates among three groups: all who enrolled the course, all who submitted the pre-course survey, and all who submitted the first individual assignment.

We then used basic descriptive statistics to compare the proportion of participants who completed all course assignments by the types of supports they received, including no supports. To more deeply understand the relationship between supports and completion, we used logistic regression to analyze whether types of supports were significantly related to course completion. We constructed a series of models, all of which had course completion as the outcome. We first tested the relationship between receiving any support and course completion and then tested the relationship between the number of supports participants received (including no supports) and course completion. Finally, we introduced a variety of demographic controls into the model. The control variables were participants' years of teaching experience, the grade level participants currently taught (if any), whether participants currently worked as classroom teachers, whether participants currently worked with English learners, whether participants had taken an online course previously, and whether participants had taken a course about classroom discourse previously. All demographic controls were based on information provided by participants in the pre-course survey.

Finally, to better understand the types of supports provided by districts, we conducted interviews with instructional leaders in two focal districts. These two districts had the most teachers complete the online professional development course. In our interviews with district leaders, we gathered detailed information about the specific features of the multi-layered support structures they designed, as well as their reflections about the effectiveness of the different aspects of these support structures. We reviewed transcripts of these interviews to identify similarities and differences between the types of support structures and similarities and differences in their reflections about the most effective aspects of these supports.

\section{Relationship between Supports and Learning within the Course}

To address our second research question, concerning teacher learning, we examined what participants learned from the course along with the relationship between supports and learning 
within the course. Across these analyses, we used a variety of data sources and methods to measure participants' learning.

First, we examined participants' responses to two open-ended post-course survey questions about how their learning in the course had impacted their teaching. These two questions asked participants to reflect on how they had already changed their instructional practices and how they planned to change their instructional practices. Second, we examined participants' online assignment submissions. In particular, we analyzed participants' final assignment where they were asked to create either: 1) a presentation detailing what they learned from the course that they could share with colleagues; or 2) a lesson plan that showcased what they learned about argumentation. ${ }^{2}$ As part of this assignment, participants responded to two reflection questions about their learning. Participants' writings offered rich qualitative data, as the assignment was a synthesis and explanation of what they had learned throughout. We reviewed participants' responses to these survey questions and final assignments, developed codes for themes that emerged, and analyzed the frequency of these themes.

For our second analysis, we examined participants' learning as reflected in the post-course survey. The post-course survey asked participants to identify specific learning from the course, and we tabulated these to explore their prevalence across participants. Building on these two preliminary analyses, we examined the relationship between supports and learning in the course.

For our third analysis, we used data from the Likert-scale questions from both the pre- and post-course surveys. On both surveys participants self-reported how knowledgeable they felt about argumentation and how prepared they felt to set-up and facilitate argumentation. On the postcourse survey, participants also rated how prepared they felt to change their instructional practice and how satisfied they were with what they learned in the course. We tabulated participants' postcourse Likert scale ratings and compared participants' post-course ratings to their pre-course ratings, looking for evidence of change over time. Then, to determine whether there was a relationship between self-reported learning and whether teachers received supports to participate, we conducted a series of ordered logistic regression analyses. In these analyses, the post-course Likert-scale ratings were the dependent variable and information about the types and numbers of supports each participant received were the key independent variables. In our final models, we also included a set of demographic covariates drawn from the pre-course survey (the same demographic covariates listed above for Research Question 1, analysis 3).

Finally, we constructed a novel direct measure of learning. This analysis was motivated by calls for MOOC research to include direct measures of learning (Reich, 2015). Specifically, we measured whether participants' ratings of student argumentation transcripts became more like experts' ratings. ${ }^{4}$ To do this, we constructed a measure of the distance between the participant's ratings and experts' ratings. We then compared changes in this measure over time for teachers who did and did not receive structural and social supports.

As shown in Equation 1, for each of the three dimensions of the Argumentation Analysis Tool, we calculated the distance, $d$, between each participant's rating, $p$, and experts' rating, $e$, of that dimension, following procedures previously used by Rutherford-Quach et al. (2015). In Equation 1, each of the three dimensions on which the argumentation sample was rated is indexed by $x$ and each participant is indexed by $i$. The variable $t$ indexes the timeframe of the rating, indicating whether the rating came from the pre- or post-course survey. For each dimension at each 
time point, we simply subtracted the expert rating from the participant's rating at that time point and squared the result.

$$
d_{x i t}=\left(p_{x i t}-e_{x}\right)^{2}
$$

To determine a single estimate of the difference, $D$, between the participant's ratings and the experts' ratings, we summed the result for each of the three dimensions and then computed the square root, as illustrated in Equation 2. Higher values occurred when there were greater differences between participants' ratings and experts' ratings, while lower values occurred when there was more alignment between participant and expert ratings.

$$
D_{i t}=\sqrt{d_{1 i t}+d_{2 i t}+d_{3 i t}}
$$

To determine whether there was a change in the difference between participant and expert ratings over time, we conducted a simple t-test between the sample means for the measures at each time point, comparing $D_{\text {ipre }}$ and $D_{\text {ipost }}$.

To explore the relationship between supports for course participation and participants' learning, we then constructed a measure showing change in the difference between participant ratings and expert ratings before and after the course:

$$
D_{i}=D_{\text {ipost }}-D_{\text {ipre }}
$$

We used this measure as an outcome in regression models, exploring whether receiving supports for course participation had a significant impact on rating argumentation samples. Again, in our final model, we included a set of demographic covariates drawn from the pre-course survey.

\section{Results}

\section{Online Course Completion and Supports}

Analysis 1.1: Types of supports participants received. Before analyzing the relationship between completion rates and the types of supports that participants received from their districts, it is useful to understand more about the types of supports and their prevalence. Following our theoretical framework, the structural and social supports available to some participants were local conditions of the learning environment, which may have impacted engagement and learning. We examined two possible structural supports, stipends and release time, which may have impacted the feasibility of participation, and two possible social supports, participating in the course with a colleague and having a facilitator who convened in-person meetings, which may have increased the social incentives to participate. Recall that we only have information about types of supports provided for participants who indicated in the pre-survey that they were Oregon teachers $(n=427)$. Among the Oregon course participants, 67\% reported receiving some type of support from their school or district. As Figure 2 indicates, the most common type of support was taking the course alongside a group of colleagues from the same school or district (54\%), followed by receiving a stipend (18\%), meeting with a facilitator $(15 \%)$, and having release time to engage in courserelated activities (13\%). Figure 3 shows a histogram of the numbers of types of supports that Oregon participants reported receiving. Twenty-four percent of Oregon participants reported receiving more than one type of support. For example, all respondents who indicated having a stipend, a facilitator, and/or release time also reported participating in the course with colleagues. Thus, some participants received a mixture of structural and social supports. 


\section{Figure 2}

Supports for MOOC Participation Reported by Oregon Teachers

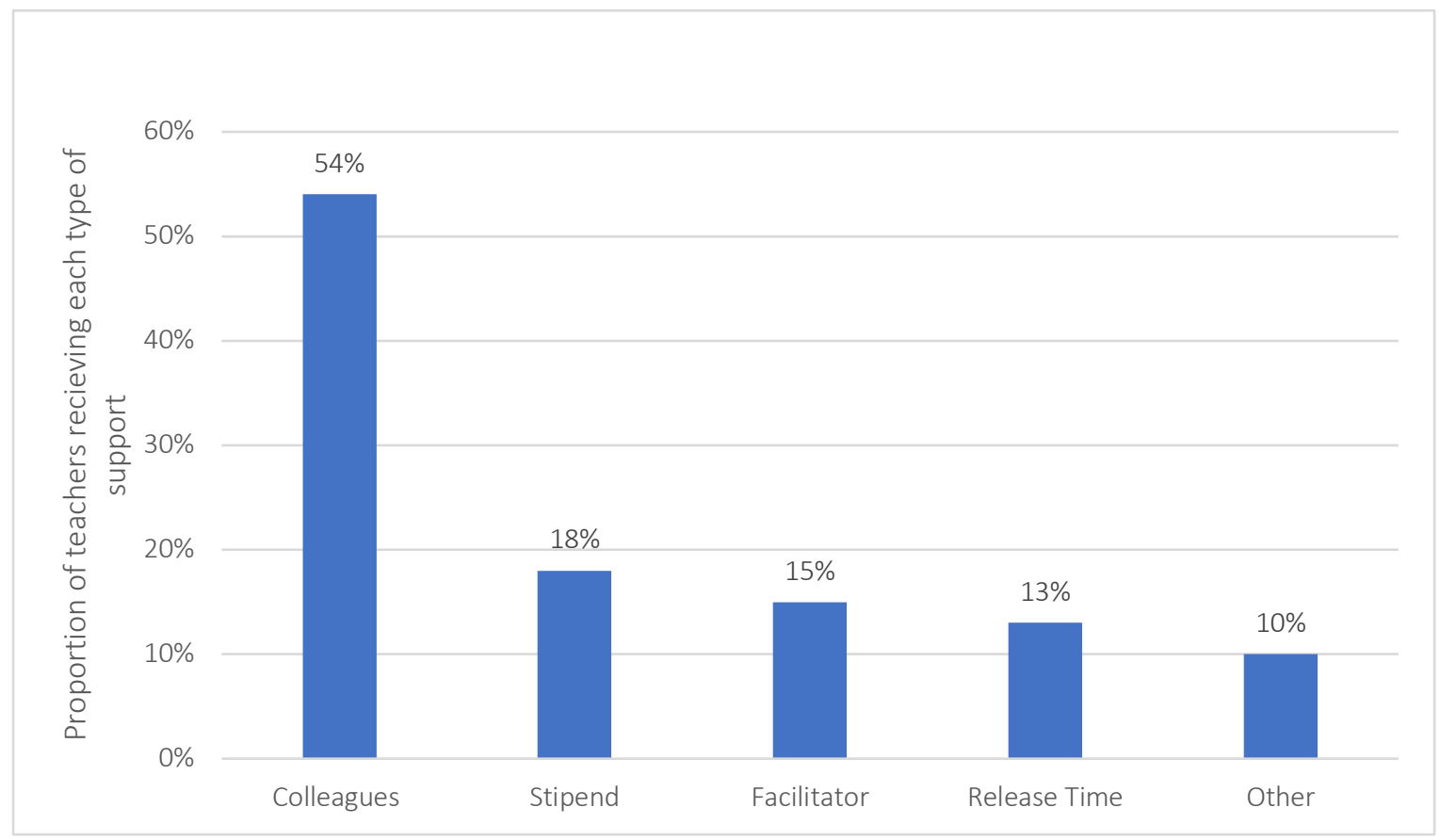

Note. Respondents could indicate receiving more than one type of support.

\section{Figure 3}

Number of Types of Supports Reported by Oregon MOOC Participants 
The Role of Supports in Completion and Learning in Online Professional Development for Teachers

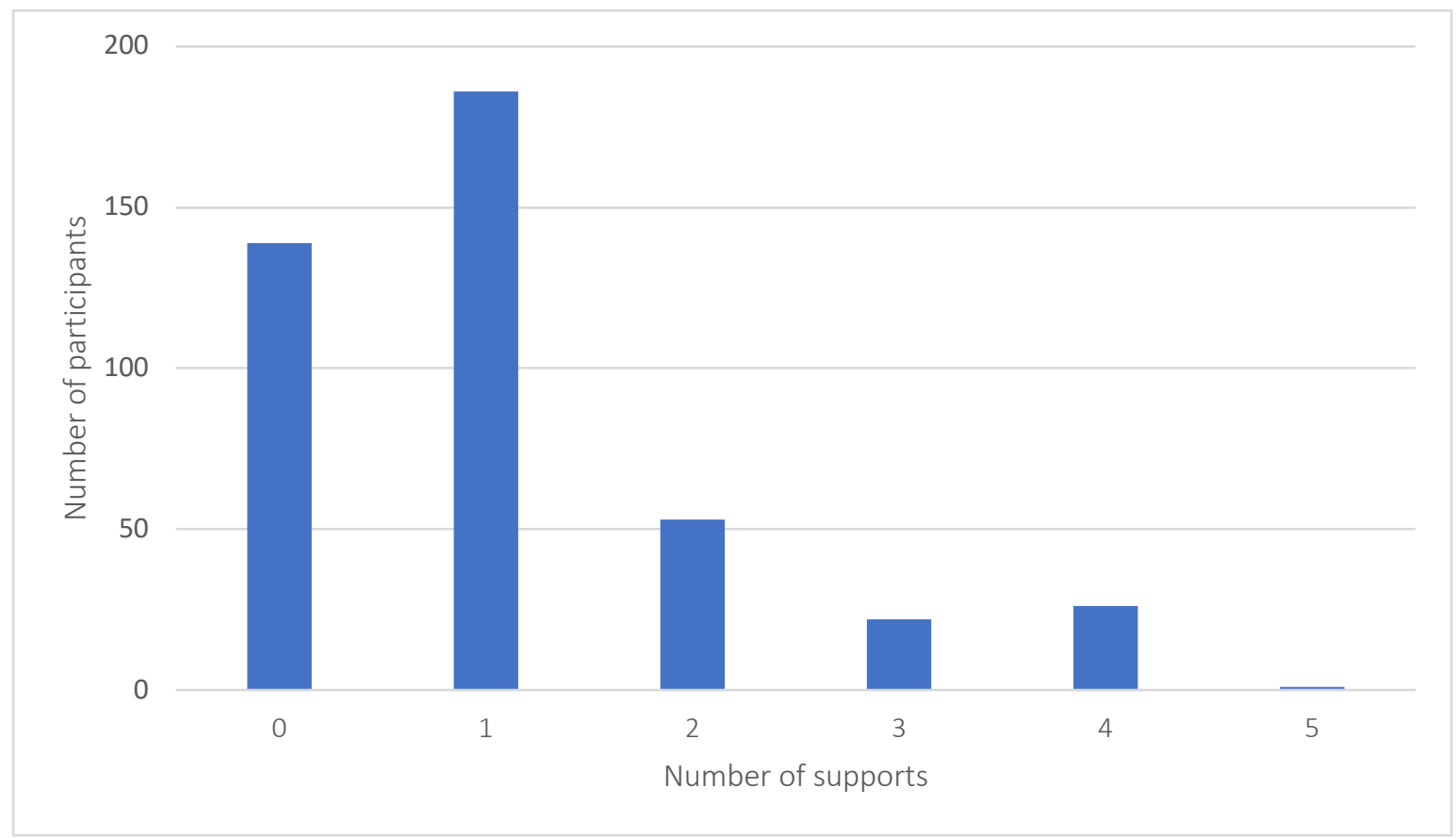

Analysis 1.2: Overall course completion rates. As is typical of free online courses, a small proportion of those who enrolled in the online course completed all the individual assignments. As other researchers have pointed out, many individuals enroll in online courses without ever intending to complete them (Clow, 2013; DeBoer, Ho, Stump, \& Breslow, 2014; Jordan, 2015; Koller, Ng, Chuong, \& Chen, 2013; Wang \& Baker, 2015). Therefore, it is also useful to calculate the proportion of participants who completed the course out of the participants who completed the first assignment, which we refer to as the adjusted completion rate. As Table 2 shows, 5\% of those who enrolled in the course completed all three individual assignments. Among those who completed the pre-course survey, the completion rate was $11 \%$. Among those who completed the more time-intensive first individual assignment, which involved recording, transcribing, and analyzing an oral language sample of argumentation, the completion rate (i.e., the adjusted completion rate) was 59\%.

\section{Table 2}

Completion of all Individual Assignments for the MOOC among Participants Completing Different Initial Steps

\begin{tabular}{lrrr}
\hline \multicolumn{1}{c}{ Group } & Total & $\begin{array}{r}\text { Number } \\
\text { completing }\end{array}$ & $\begin{array}{r}\text { Percentage } \\
\text { completing }\end{array}$ \\
\hline Among all who enrolled in the course & 5,102 & 250 & $5 \%$ \\
Among all who submitted the pre-course survey & 2,093 & 227 & $11 \%$ \\
Among all who submitted the first individual & 424 & 250 & $59 \%$ \\
assignment & & & \\
\hline
\end{tabular}

Analysis 1.3: Tabulations of completion rates by types of supports received. With this information about types of supports and completion rates, we were then able to more directly examine of our first research question, comparing completion rates for participants who received different types of supports. (See Table 3.) Those who received any type of support were more 
likely to complete the course than those who received no support (25\% completion among those receiving no support compared to $35 \%$ among those receiving some support). However, particular types of supports and combinations of supports were associated with substantially higher completion rates. As noted above, participating alongside a colleague was the most common type of support. A higher proportion of those who received this support completed the course when compared to those who received no support ( $38 \%$ compared to $25 \%$, respectively). However, all other supports were associated with higher completion rates. For example, over half of participants receiving any type of structural support (release time or stipends) completed the course $(57 \%$ completion for those receiving release time and $51 \%$ for those receiving a stipend). Importantly, all participants receiving a stipend or release time also participated in the course with colleagues, so we cannot determine the association between these structural supports and completion independent of their receiving the social support of participating with colleagues. Among those who received even more types of supports, completion rates were even higher. For example, $70 \%$ of those who had release time, had a facilitator, and participated with colleagues completed the course. Similarly, $74 \%$ of participants who received a stipend, had release time, and participated with colleagues completed the course.

\section{Table 3}

Completion of All Individual Assignments for the MOOC by Types of Support Received, among Oregon Teachers

\begin{tabular}{lrrr}
\hline \multicolumn{1}{c}{ Group } & Total & $\begin{array}{r}\text { Number } \\
\text { completing }\end{array}$ & $\begin{array}{r}\text { Percentage } \\
\text { completing }\end{array}$ \\
\hline Receiving no support & 139 & 35 & $25 \%$ \\
Receiving some support & 288 & 100 & $35 \%$ \\
Participating with school/district colleagues & 232 & 89 & $38 \%$ \\
Release time + participating with colleagues & 56 & 32 & $57 \%$ \\
Stipend + participating with colleagues & 75 & 38 & $51 \%$ \\
Facilitator + participating with colleagues & 64 & 30 & $48 \%$ \\
Other support & 41 & 12 & $29 \%$ \\
Facilitator + stipend + participating with colleagues & 32 & 19 & $59 \%$ \\
Facilitator + time + participating with colleagues & 33 & 22 & $67 \%$ \\
Stipend + time + participating with colleagues & 27 & 20 & $74 \%$ \\
Facilitator + time + stipend + participating with colleagues & 23 & 16 & $70 \%$ \\
\hline
\end{tabular}

Analysis 1.4: Logistic regression models of the relationship between course completion and types of support. We then used inferential statistics to test the relationship between course completion and types of supports. Results from a series of logistic regression models demonstrated a significant positive relationship between receiving supports for course participation and completing the course. As shown in Table 4, results from Model 1 show that participants receiving any supports were significantly more likely than others to complete the course $(p<.05)$. Models 2 and 3 show that the more supports that participants received, the more likely they were to complete the course $(p<.001$ for the joint test of significance for a series of indicators for each possible value of the variable for types of support). Model 4 demonstrates that this significant, positive relationship remains $(p<.001$ for the joint test) after controlling for a variety of demographic factors (current role as a classroom teacher, current work with English learners, years of teaching experience, grade level taught, prior participation in an online course, and prior participation in a course about classroom discourse). Figure 3 presents the results for 
Model 4 graphically, showing the fitted probability of receiving different numbers of supports. Results from this final model indicate that those receiving four types of supports had a $77 \%$ likelihood of completing the course compared to a $27 \%$ likelihood for those receiving only one type of support.

\section{Table 4}

Relationship between Course Completion and Receiving Supports, among Oregon Teachers

\begin{tabular}{|c|c|c|c|c|c|c|c|}
\hline & Model 1 & Model 2 & & Model 3 & & Model 4 & \\
\hline Any support & $\begin{array}{r}0.470 \\
-0.235\end{array}$ & * & & & & & \\
\hline Types of support & & $\begin{array}{r}0.477 \\
(-0.098)\end{array}$ & $* * *$ & & & & \\
\hline 1 support & & & & $\begin{array}{r}0.088 \\
(0.260)\end{array}$ & & $\begin{array}{r}0.022 \\
(0.268)\end{array}$ & \\
\hline 2 supports & & & & $\begin{array}{r}0.658 \\
(0.344)\end{array}$ & + & $\begin{array}{r}0.552 \\
(0.359)\end{array}$ & \\
\hline 3 supports & & & & $\begin{array}{r}0.878 \\
(0.491)\end{array}$ & + & $\begin{array}{r}0.932 \\
(0.514)\end{array}$ & + \\
\hline 4 supports & & & & $\begin{array}{r}2.283 \\
(0.506)\end{array}$ & $* * *$ & $\begin{array}{r}2.213 \\
(0.527)\end{array}$ & $* * *$ \\
\hline Demographic covariates & & & & & & $\mathrm{X}$ & \\
\hline Log likelihood & -258 & -247 & & -245 & & -238 & \\
\hline $\mathbf{N}$ & 414 & 414 & & 414 & & 414 & \\
\hline Test & 0.045 & 0.000 & & 0.000 & & 0.000 & \\
\hline
\end{tabular}

Notes. ${ }^{* * *} p<.001 ; * * p<.01, * p<.05$. Standard errors appear in parentheses below coefficient estimates. For Model 1 , the value of Test shows the p-value for the test of significance for the continuous variable for types of support. For Models 2 and 3, the value of Test shows the p-value for the joint test of significance for a series of indicators for each possible value of the types of support variable.

\section{Figure 3}

Fitted Probability of Course Completion by Number of Supports Received, among Oregon Teachers

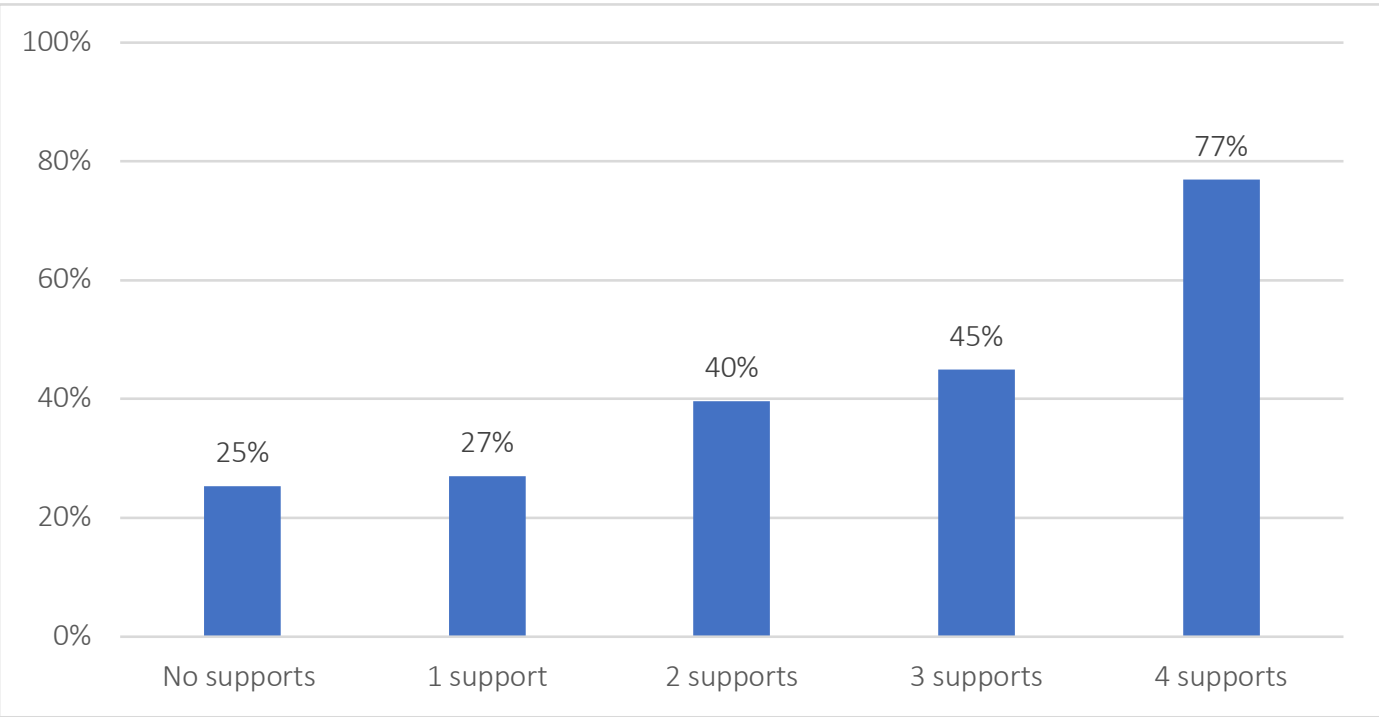


Analysis 1.5: Qualitative analysis of support structures in focal districts. To more fully understand the ways in which multi-layered support structures for course participants functioned, we drew on interviews with administrators in the focal districts. These two districts had the largest number of participants complete the online argumentation course among all Oregon districts. Both also offered participants all possible supports examined in this study: stipends, release time, joint engagement in the course with colleagues, and facilitators.

In both districts, regular, in-person meetings led by facilitators were a key component of the support structure for course participants. In District A these meetings took place during the school day, with substitutes provided for participating teachers, while in District B meetings took place after school at mutually agreed-upon dates. In both districts, participants who completed all course requirements and also attended a specific number of in-person meetings received a stipend. In some cases, the in-person meetings functioned as collaborative work sessions, with participants watching the course videos together, discussing readings, and planning for upcoming assignments. In other cases, facilitators led simulations of classroom strategies shown in course videos, giving participants direct experience with the strategy and then reflecting on its application to participants' classrooms. The District A leader described opting to create more rather than less structure for these in-person meetings, explaining that they provided "a very hand-held version, especially at first," distributing handouts of assignment instructions, ensuring that participants could access the content via the course website, and removing other barriers to successful engagement in the course before focusing on more substantive discussions. Thus, the district supports may have made ongoing participation in the course more feasible for participants.

One important element of the support offered by District A was that English Language Development (ELD) teachers and content-area teachers were required to form partnerships that lasted for the duration of the course. For example, an ELD teacher and science teacher at the same school might form a partnership, discuss a course assignment focused on designing a lesson plan incorporating argumentation and co-design lesson plans for their respective classes during an inperson meeting, and then meet to discuss what happened when they taught those lessons. In this way, the ELD teacher could draw on the expertise of the science teacher to effectively integrate science content into the language-focused ELD lesson plan. In addition, the science teacher could draw on the expertise of the ELD teacher to effectively integrate language development into her science lesson. Reflecting on the benefits of this partnership model, the District A leader said:

I think our ELD staff really was intrigued by the idea of inviting content-area teachers into that conversation and trying to talk about the new standards with a content teacher and trying to do something with them. ... [After the course] I think that ELD teachers are ... more proficient now at analyzing the language demands of the content-area tasks that kids are being asked to do and recognizing how they can support that. So, I think that discussion has led to a better sense of collaboration. And even the other way around. I think for some of those content-area teachers, ... they're more comfortable now. It occurs to them now to go to the ELD teacher and say, "Hey, I'm teaching this. Now, what do you think?"

Similarly, the District B leader described the ways that course participants benefitted from opportunities to visit each other's classrooms, with ELD teachers having the opportunity to see what students were learning in their content area classes and vice versa. Across both districts, it is clear that the supports instructional leaders developed for participants increased opportunities for collaboration, dialogue, and social interaction — all tenets of social constructivist learning theory. 
The social incentives the district leaders provided may have facilitated communities of practice, potentially supporting participants' engagement and learning.

Leaders from both districts emphasized the variety of supports they provided to participating teachers. When reflecting on the multi-layered support structures she designed, the District A leader commented, "Every time we added a new layer of support, it took away an excuse to quit."

\section{Learning in the Online Course and Supports}

Analysis 2.1: Qualitative evidence of learning within the online course. To address the second research question concerning the relationship between receiving supports for course participation and participants' learning, we first explored what participants appeared to learn in the professional development course. As noted above, we analyzed responses to two open-ended post-course survey questions about how participants had already changed their instructional practices and how they planned to change their instructional practices. In addition, we analyzed participants' reflections on the course from their final assignments.

Increased awareness of argumentation. A major theme that emerged in participants' responses to the two qualitative survey questions we analyzed $(n=319)$ was an increased awareness of argumentation. For instance, in response to the first question, about ways in which participants had already changed their instructional practices with respect to argumentation, 114 respondents $(35 \%)$ reported that as a result of what they learned in the course they were now teaching argumentation in their classes or discussing argumentation in their work with other teachers, indicating an increased awareness of argumentation and its role in instruction. The code we created for these responses, 'now I teach argumentation,' was the most frequently occurring code for this survey question. The theme of increased argumentation awareness was even stronger when we analyzed participants' responses to the second qualitative survey question, which asked about if and how respondents were planning to change their instructional practice. Specifically, 197 respondents $(60 \%)$ reported that they were planning to change their practices to incorporate argumentation more fully.

Two subthemes were particularly salient within the broad 'increased awareness of argumentation' category. First, participants indicated that they were more attuned to various opportunities to integrate argumentation in their lessons. One participant coined the phrase 'argumentation ears' to describe the ability she had developed to recognize these opportunities. We subsequently adopted this as a code (see below). Second, participants reported that they had also become more aware of the cross-curricular nature of argumentation, realizing that argumentation can be used across the content areas. In the following sections we explore the subthemes of 'argumentation ears' and the cross-curricular dimensions of argumentation.

Argumentation ears. Beyond developing a more nuanced understanding of what argumentation is, a substantial number of participants noted that the course allowed them to develop their 'argumentation ears' - that is, their ability to identify opportunities for embedding argumentation in their lessons. The 'argumentation ears' theme was salient in participants' answers to what they had already changed in their practice, in what they were planning to change, and in their final assignments.

For instance, one participant pointed out that argumentation is a strategy that can be used with younger students. In her words, "Before this course, I did not have my younger students tell 
me why they gave me their answers. Now I find myself asking questions that make them think and question, '[I]s that correct?' I have received some amazing answers." In their final assignments participants also addressed the complexity of argumentation and how to scaffold students' understanding of the argumentation process. One participant, for instance, indicated that, "[T]he insight that really struck home is that [argumentation] is far more complex than just making a case and giving a reason." Other participants described this complexity in terms of the various components that make up an argument noting, "I really learned the parts that students need to have in order to successfully argue their point. In the past I thought an argument was pretty easy to do, but to do it correctly there are several components."

Cross-curricular nature of argumentation. When reflecting on their course experiences, many participants described their heightened awareness of the cross-curricular nature of argumentation. Specifically, participants pointed out the various ways in which they found argumentation applicable across different subjects when describing how they had already changed their practice and what they were planning on doing in the future. They also described their conceptual insights regarding the cross-curricular nature of argumentation-how it is endemic to nearly every subject and grade level —in their final assignments.

For example, in the final assignment one participant reported gaining "more insight on how argumentation works for all students. It is a strategy that can be taught in any grade and any content [area]." This realization seemed to have particularly affected content-area teachers or those who work with content area teachers, such as instructional coaches. As another participant-an instructional coach-explained, "In the last few weeks, I have realized that there are so many opportunities in all content areas to teach argumentation skills."

This realization also seemed to serve as a wake-up call regarding the importance of content teachers attending to language practices such as argumentation and the need for English language development and content area teachers to collaborate. In line with the observations of district leaders, one participant noted, "Argumentation should not only occur during ELD instruction; but rather, argumentation is at the heart of the new CCSS and Next Generation Science Standards. In order to effectively reach our EL populations, content and language need to be connected during the entire school day."

Analysis 2.2: Teacher learning from the course. To gather additional information about what participants learned in the course, we also examined reports from the post-course survey. When selecting from a list of eight possible learning outcomes, post-course survey respondents were most likely to identify the major components of argumentation, selected by $80 \%$ of respondents. As indicated in Table 5, this appears to be a foundational understanding, something of a precursor to other possible learning outcomes, such as how to model/scaffold argumentation skills and how to set the stage for argumentation in the classroom. This parallels our analysis of open-ended survey questions and the final assignment, which indicated that increased awareness of argumentation components was the primary theme, followed by greater understanding of how to support student engagement in argumentation. 


\section{Table 5}

Number and Proportion of Post-Course Survey Respondents Indicating Particular Items Were Key Learning Outcomes from the Argumentation MOOC

\begin{tabular}{lcc}
\multicolumn{1}{c}{ Outcome } & $\begin{array}{c}\text { Number of } \\
\text { respondents selecting } \\
\text { item as key outcome }\end{array}$ & $\begin{array}{c}\text { Percentage of } \\
\text { respondents selecting } \\
\text { item as key outcome }\end{array}$ \\
\hline $\begin{array}{l}\text { What argumentation components are (i.e., claims, } \\
\text { evidence, reasoning) }\end{array}$ & 263 & $80 \%$ \\
$\begin{array}{l}\text { How to model and/or scaffold argumentation skills } \\
\text { (i.e., making a claim, providing support for the claim, }\end{array}$ & 228 & $69 \%$ \\
$\begin{array}{l}\text { evaluating the quality of support for a claim, using } \\
\text { language to convey relationships among key ideas) }\end{array}$ & & \\
$\begin{array}{l}\text { How to set the stage for argumentation in the } \\
\text { classroom }\end{array}$ & 208 & $63 \%$ \\
$\begin{array}{l}\text { What makes an effective argument } \\
\text { How to analyze student-to-student conversations } \\
\text { using the Argument Analysis Tool (AAT) }\end{array}$ & 203 & $62 \%$ \\
$\begin{array}{l}\text { How to use argumentation analysis to plan future } \\
\text { lessons, interactions, and interventions }\end{array}$ & 202 & $61 \%$ \\
$\begin{array}{l}\text { Importance of argumentation } \\
\text { Link between this work and Common Core State }\end{array}$ & 195 & $59 \%$ \\
Standards requirements & 157 & $48 \%$ \\
Other & 140 & $43 \%$ \\
\hline
\end{tabular}

Analysis 2.3: The relationship between Likert scale self-reports of learning and supports. Next, turning to a more direct examination of the relationship between learning and supports we analyzed participant ratings of their course-related knowledge before and after the course. Then having constructed variables showing any changes in participant knowledge over time, we tested whether receiving supports was significantly related to these changes. Both the pre- and post-course survey included a variety of Likert-scale questions about participant knowledge of argumentation. In the post-course survey, $86 \%$ reported feeling knowledgeable, very knowledgeable, or extremely knowledgeable about supporting students in constructing arguments, which was one of the four course outcomes. Seventy-four percent of respondents reported feeling well-prepared, very well-prepared, or extremely well-prepared to set up and facilitate argumentation. Eighty-two percent reported being satisfied or very satisfied with what they learned about instructing argumentation. When comparing individuals' pre- and post-course responses to how knowledgeable they felt about argumentation and how prepared they felt to facilitate argumentation in their classrooms, we saw increases of 1.08 and 1.12 Likert-scale points, respectively, on a five-point scale. In other words, if on the pre-survey, a participant reported feeling "somewhat knowledgeable" about argumentation (a value of 2 on the five-point Likert scale), on the post-survey, the participant was likely to report feeling "knowledgeable" about argumentation (a value of 3 on the five-point Likert scale, an increase of one point).

Table 6 presents results from ordered logistic regression models testing the relationship between four Likert-scale questions about learning outcomes on the post-course survey and receiving supports. Although there were several exceptions, in general (across ten out of twelve 
models), there appeared to be no significant relationship between receiving supports for course participation and participants' self-reported learning from the course, regardless of how the support variable is operationalized. ${ }^{5}$ Furthermore, the negative sign on the coefficients of the support variable(s) indicates that those receiving supports tended to report lower levels of learning than those who received no supports. Importantly, those who completed the course without supports may have differed from those who completed the course with supports - such as having greater motivation, greater interest in the material, and/or more experience with self-directed learning. We elaborate on this in the discussion section.

\section{Table 6}

Relationship between Likert-Scale Post-Course Survey Questions about Learning Outcomes and Receiving Supports, among Oregon Teachers

\begin{tabular}{|c|c|c|c|c|c|c|c|c|c|c|c|c|c|}
\hline & \multicolumn{4}{|c|}{$\begin{array}{l}\text { How knowledgeable do you } \\
\text { currently feel about } \\
\text { supporting students in } \\
\text { constructing arguments? }\end{array}$} & \multicolumn{4}{|c|}{$\begin{array}{l}\text { How well prepared do you } \\
\text { currently feel you are to set-up } \\
\text { and facilitate argumentation in } \\
\text { your classroom? }\end{array}$} & \multicolumn{5}{|c|}{$\begin{array}{l}\text { How satisfied are you with what you } \\
\text { learned about supporting students in } \\
\text { engaging in argumentation? }\end{array}$} \\
\hline & M1 & M2 & M3 & M4 & M1 & M2 & M3 & M4 & M1 & M2 & M3 & M4 & \\
\hline Any support & $\begin{array}{l}-0.226 \\
(0.400)\end{array}$ & & & & $\begin{array}{l}-0.145 \\
(0.388)\end{array}$ & & & & $\begin{array}{l}-0.518 \\
(0.424)\end{array}$ & & & & \\
\hline $\begin{array}{l}\text { Types of } \\
\text { support }\end{array}$ & & $\begin{array}{l}-0.165 \\
(0.131)\end{array}$ & & & & $\begin{array}{l}-0.060 \\
(0.130)\end{array}$ & & & & $\begin{array}{l}-0.326 \\
(0.144)\end{array}$ & & & \\
\hline 1 support & & & $\begin{array}{l}-0.097 \\
(0.438)\end{array}$ & $\begin{array}{l}-0.116 \\
(0.458)\end{array}$ & & & $\begin{array}{l}-0.192 \\
(0.424)\end{array}$ & $\begin{array}{l}-0.025 \\
(0.444)\end{array}$ & & & $\begin{array}{l}-0.310 \\
(0.468)\end{array}$ & $\begin{array}{l}-0.215 \\
(0.512)\end{array}$ & \\
\hline 2 supports & & & $\begin{array}{l}-0.109 \\
(0.542)\end{array}$ & $\begin{array}{l}-0.212 \\
(0.561)\end{array}$ & & & $\begin{array}{c}0.076 \\
(0.533)\end{array}$ & $\begin{array}{c}0.174 \\
(0.563)\end{array}$ & & & $\begin{array}{l}-0.332 \\
(0.604)\end{array}$ & $\begin{array}{l}-0.253 \\
(0.648)\end{array}$ & \\
\hline 3 supports & & & $\begin{array}{l}-0.262 \\
(0.727)\end{array}$ & $\begin{array}{l}-0.193 \\
(0.784)\end{array}$ & & & $\begin{array}{c}0.338 \\
(0.693)\end{array}$ & $\begin{array}{c}0.468 \\
(0.745)\end{array}$ & & & $\begin{array}{l}-0.310 \\
(0.788)\end{array}$ & $\begin{array}{l}-0.209 \\
(0.891)\end{array}$ & \\
\hline 4 supports & & & $\begin{array}{l}-0.753 \\
(0.583)\end{array}$ & $\begin{array}{l}-0.838 \\
(0.620)\end{array}$ & & & $\begin{array}{l}-0.567 \\
(0.583)\end{array}$ & $\begin{array}{l}-0.437 \\
(0.622)\end{array}$ & & & $\begin{array}{l}-1.577 * \\
(0.632)\end{array}$ & $\begin{array}{l}-1.997 \\
(0.701)\end{array}$ & $* *$ \\
\hline $\begin{array}{l}\text { Demographic } \\
\text { covariates }\end{array}$ & & & & $\mathrm{X}$ & & & & $\mathrm{X}$ & & & & $\mathrm{X}$ & \\
\hline Log-likelihood & -138 & -137 & -137 & -133 & -158 & -158 & -157 & -154 & -117 & -115 & -115 & -103 & \\
\hline $\mathbf{N}$ & 131 & 131 & 131 & 131 & 131 & 131 & 131 & 131 & 131 & 131 & 131 & 131 & \\
\hline Test & 0.573 & 0.209 & 0.750 & 0.729 & 0.709 & 0.645 & 0.756 & 0.822 & 0.221 & 0.024 & 0.154 & 0.047 & \\
\hline
\end{tabular}

Notes. ${ }^{* * *} p<.001 ; * * p<.01, * p<.05$. Standard errors appear in parentheses below coefficient estimates. For Model 1 , the value of Test shows the p-value for the test of significance a dichotomous variable indicating whether a participant indicated receiving any district support. For Model 2, the value of Test shows the p-value for the test of significance for a continuous variable indicating the number of types of support a participant indicated receiving. For Models 3 and 4, the value of Test shows the p-value for the joint test of significance for a series of indicators for each possible value of the types of support variables. 
Because of the relatively small sample size of Oregon teachers who completed both the pre- and post-course survey $(N=131)$, we do not have the ability to run complex models exploring the relationship between self-reported learning outcomes and a broad set of additional factors. However, exploratory analysis of the broader sample of all participants with complete pre- and post-course survey responses $(N=222)$ suggests that participants who reported finding the online course platform easier to use were likely to have more positive responses to questions related to learning outcomes. (Full results are available from the authors.) It may be no surprise that participants who found the online course platform easier to use learned more and were more satisfied with the course than their peers. Nonetheless, it serves as a reminder that, as indicated in our theoretical framework, both learner characteristics and features of the learning environment may play important roles in shaping participants' learning in online professional development.

Analysis 2.4: The relationship between supports and a direct measure of learning. As noted above, we also designed a measure to directly assess whether participant ratings of student argumentation samples became more like expert ratings. We did this by comparing the difference between participant ratings of argumentation transcripts to expert ratings before and after the course. Results showed significant evidence of learning using this outcome measure. Specifically, results demonstrated that participant ratings were more similar to expert ratings after the course than they were before the course began. Across the three dimensions of the Argumentation Analysis Tool, Oregon participant ratings were, on average, 2.33 points away from expert ratings before the course. By the end of the course, the gap between participant and expert ratings had narrowed to 1.06 points. A $t$-test of the sample means at each time point indicates that this change was statistically significant $(p<.001)$.

While the information presented above provides evidence of teacher learning, we performed further analyses to understand the relationship between learning and receiving supports. Regression models indicated participants receiving supports did not show more evidence of learning than their peers who completed the course without supports. Specifically, Oregon teachers receiving supports did not show changes in transcript ratings that were significantly different from participants who were not receiving supports. As Figure 4 illustrates, among Oregon teachers receiving supports, the mean difference between participant and expert ratings before the course was 2.35. By the end of the course, the gap between participant and expert ratings had fallen to 1.06 , a drop of 1.29 points. For Oregon teachers receiving no supports, results were very similar. At the start of the course, the gap between participant and expert ratings was 2.28 points among participants receiving no support. By the end of the course, this gap had close to 1.09 points, a drop of 1.18 points. 


\section{Figure 4}

Changes in the Difference between Participant and Expert Transcript Ratings before and after the Course, among Oregon Teachers Receiving and Not Receiving Supports for Course Participation

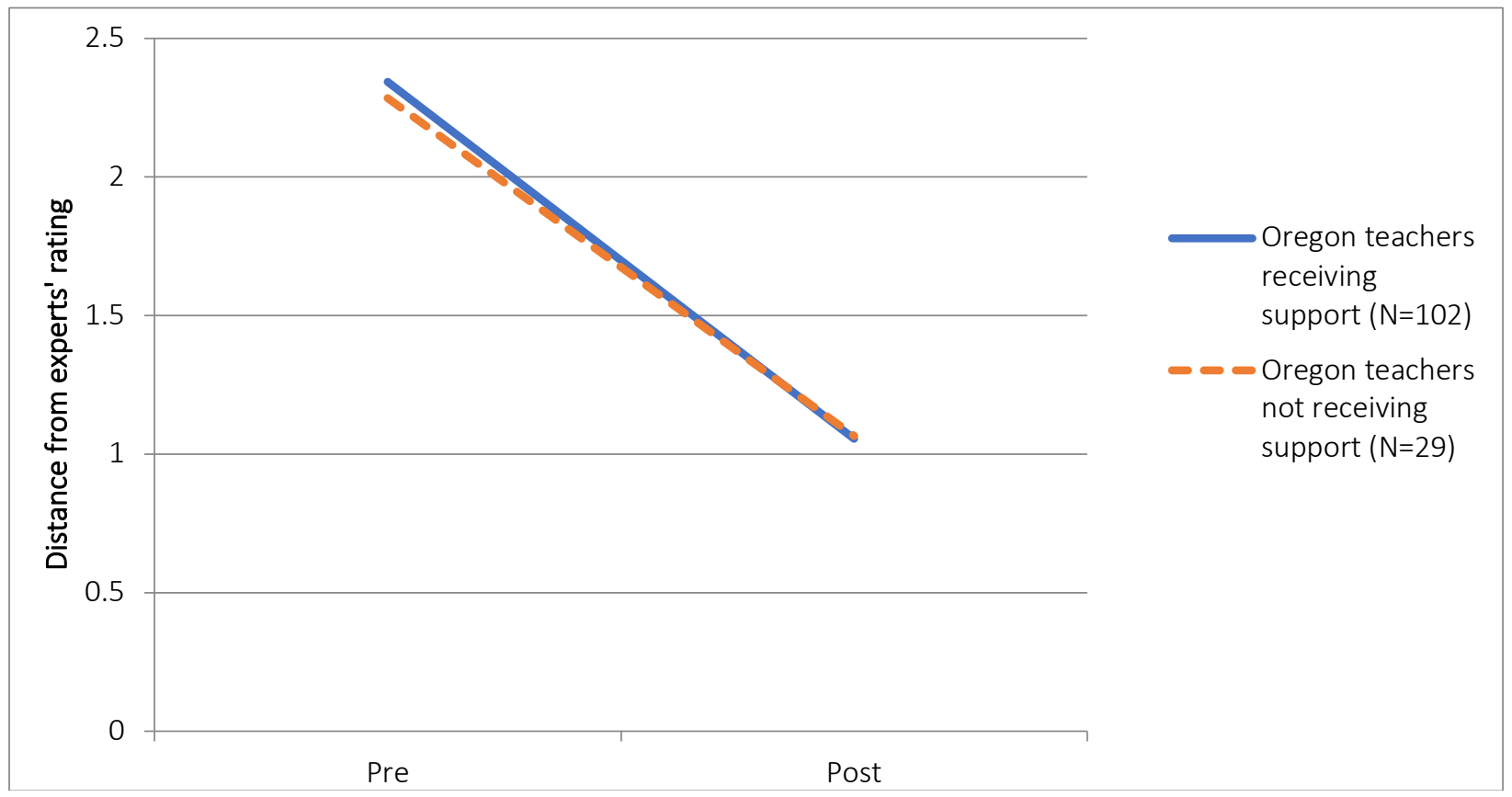

Note. Only participants' data with both pre- and post-course transcript ratings are included.

Table 7 presents a series of regression models providing further evidence that there was no statistically significant relationship between changes in transcript ratings and receiving supports for course participation. Specifically, there is no statistically significant relationship between changes in transcript ratings and supports, regardless of how the variables for supports are constructed. Model 1 uses a dichotomous variable for receiving reports, Model 2 uses a continuous variable for types of supports received, Model 3 uses a series of indicator variables for the number of supports received, and Model 4 adds demographic covariates (current role as a classroom teacher, current role working with English learners, years of teaching experience, grade level taught, prior participation in an online course, and prior participation in a course about classroom discourse) to Model 3. Tests indicate that the support variable(s) are never statistically significant ( $p>.05)$. 


\section{Table 7}

Relationship between Changes in the Difference between Participants' and Experts' Transcript Ratings and Receiving Supports, among Oregon Teachers

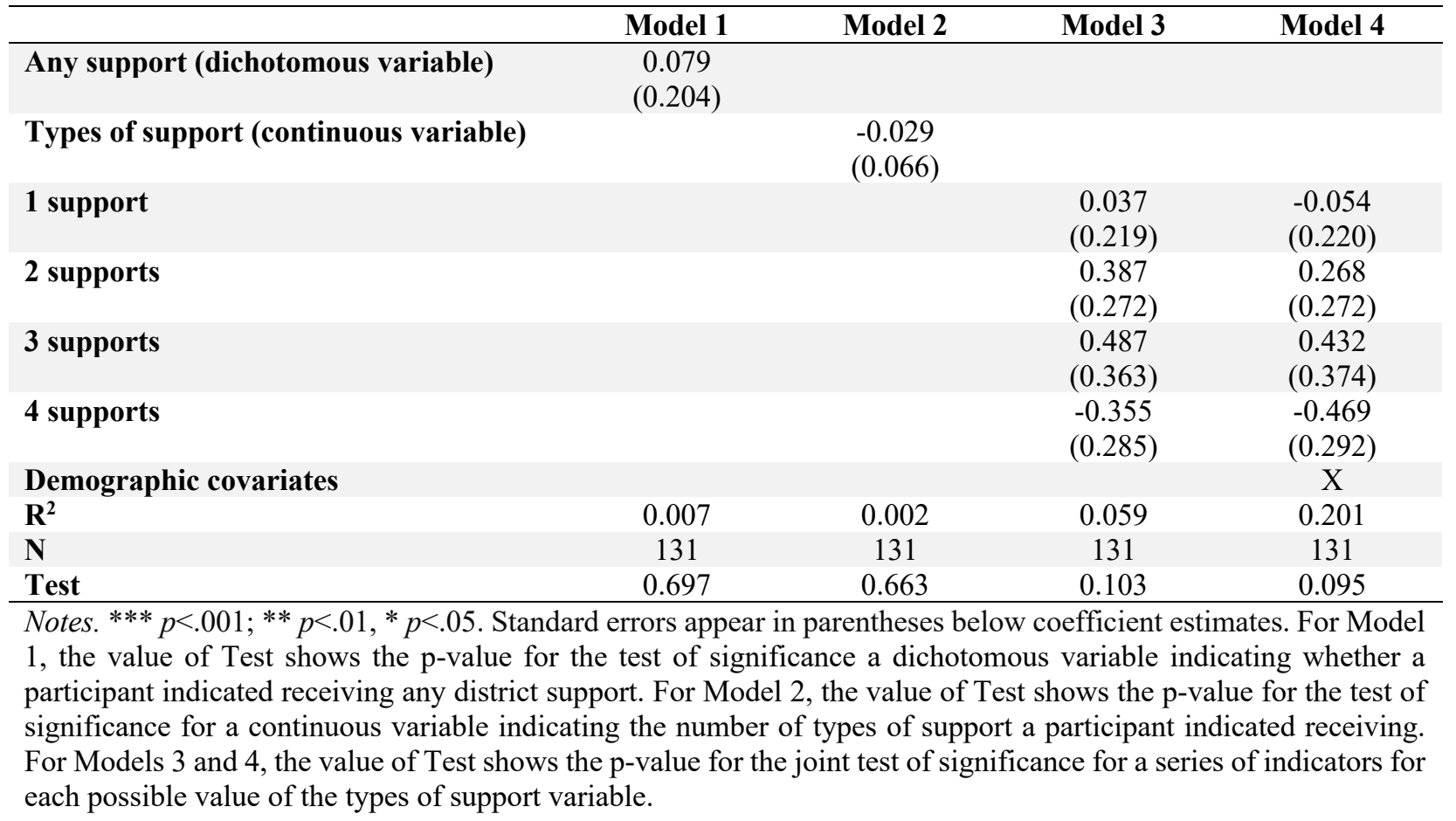

\section{Discussion}

This study investigated participant learning in an online professional development course that was specifically designed for teachers of English learners and that focused on engaging ELs in argumentation - an analytic and linguistic practice at the heart of college and career-ready standards. The research questions around which we framed our inquiry were: (1) What is the relationship between structural and social supports provided by districts and teachers' completion of the online professional development? and (2) What is the relationship between these supports and evidence of teacher learning within the course?

With respect to the first research question, findings indicated that both structural and social supports were associated with higher completion rates. Participants who received any type of support were significantly more likely to complete the course, but those receiving more resourceintensive supports and more types of supports had the highest completion rates. For example, simple tabulations of completion rates by types of supports showed that participants receiving the social support of taking the course alongside colleagues had a $38 \%$ completion rate, but those who also received the structural supports of a stipend and release time, in addition to participating alongside colleagues, had completion rates that were almost twice as high (74\%). Similarly, statistical models showed that the number of supports participants received was significantly associated with higher completion rates. Thus, we conclude that both structural supports, which may increase the feasibility of participation, and social supports, which may provide social incentives for participation and increase opportunities for interaction and dialogue, may facilitate engagement in online learning. This extends prior research about the relationship between 
contextual factors, engagement, and learning in online courses (e.g., Joksimović et al., 2018). Previous work has focused on the role of learner characteristics and features of online courses themselves (e.g., Adamopoulos, 2013; Halverson \& Graham, 2019; Joksimović et al., 2018). Here, we show that local conditions, specifically whether participants had access to structural and social supports within their school districts, are also important features of the learning environment and play a significant role in supporting teachers' engagement.

Findings from the second research question suggest that those who received structural and/or social supports did not show evidence of learning significantly more from the course than other participants. Importantly, those who received supports did show significant evidence of learning. For example, their ratings of student argumentation samples more closely resembled expert ratings at the end of the course than they did at the beginning. However, participants receiving supports did not show evidence of learning more than other participants did. Possible reasons for this finding are discussed in the limitations section below.

There are several implications for practice. First, our findings suggest that those planning online professional development for teachers, and potentially for other groups, as well, should consider providing structural and social supports for participants. Structural supports like stipends and release time may increase the feasibility of participation, and social supports like participating alongside colleagues and having a facilitator to convene in-person meetings, may increase the social incentives for participation, including increasing opportunities for interaction and dialogue. Our findings suggest that the more comprehensive supports for participating in online courses are, the more they facilitate course completion. This echoes research in other contexts, such as community colleges, which also suggest that the more comprehensive a support system is, the more successful students typically are (Karp, 2011; Scrivener et al., 2008). MOOCs are often portrayed as a low-cost alternative to in-person professional development. However, our findings suggest that to maximize potential additional investments at the local level may be important, particularly for broadening participation and increasing completion.

For teachers in under-resourced contexts, for whom MOOCs may be their only professional development option and who do not have the benefit of more resource-intensive supports such as stipends and release time provided by their districts, our findings also have several implications. First, our findings suggest that these teachers may wish to participate in MOOCs alongside a colleague. While this support appears to be associated with only a modest increase in completion rates, teachers with this support were significantly more likely to complete the course than those without this support. Thus, teachers themselves can provide this do-it-yourself support for one another. Second, state or regional education offices may wish to explicitly target funding to provide structural and/or social supports to facilitate engagement in online professional development for teachers in under-resourced contexts as Oregon did here.

Since our findings suggest that supports seem to facilitate course completion but do not necessarily enhance learning within the course - at least given the current study's limitationsboth practitioners and researchers may wish to explore additional features of online professional development, specifically how other features of the learning environment impact engagement and learning. For example, because research suggests that the learner characteristic of comfort with online learning and the online platform may play a role in learning outcomes (Garip, Seneviratne, Iacavou, 2020; Muilenburg \& Berge, 2005; Wang, Shannon \& Ross, 2013), online professional development providers and in-person facilitators may wish to devote even more attention to building participants' skills in navigating online courses. 


\section{Limitations and Directions for Future Research}

This study has two limitations we would like to address. First, it is important to remember that when analyzing data about learning outcomes, we can only analyze data from participants who completed the course. It is possible, and in fact quite likely, that participants who completed the course without supports may differ in important ways from participants who completed the course with supports. The first group may be, on average, more motivated, more skilled at self-directed learning, and/or more interested in the material. We do not have data about any of these factors from the pre-course survey and therefore cannot determine initial differences between the groups. Thus, the lack of a statistically significant difference in learning outcomes among those receiving and not receiving supports may be related to omitted variable bias.

Another limitation of the study is that the relatively small sample size of Oregon participants who completed both the pre- and post-course survey restricted our ability to more fully explore the relationship between learning outcomes and other factors. Further research is needed across a broader set of courses to better illuminate these other factors. In addition, more qualitative work is needed to illuminate in greater detail how different configurations of structural and social supports do or do not facilitate participants' course completion and learning.

Finally, while we seek to contribute to conversations about how research on professional development generally, and online professional development in particular, can directly assess participants' learning, our direct measure of participant learning - changes in the extent to which participant ratings of argumentation samples resemble expert ratings - is novel and would benefit from further study.

In conclusion, this study indicates that free online courses can serve as valuable vehicles for supporting teacher learning. Yet, for online courses to be effective and scalable professional development tools for all educators - and not just for self-starters or early adopters - our findings emphasize the potential of structural and social supports to facilitate course completion. At a time when the need for school districts to develop effective professional development initiatives that reach large numbers of teachers has reached a fever-pitch, we advocate for more research that can further illuminate features of the learning environment that support meaningful engagement and learning in online contexts.

\section{Author Note}

Creation of the MOOC described here was funded by the Oregon Department of Education. Research on outcomes for MOOC participants is funded by an Oregon State University Ecampus Research Fellowship grant, for which Dr. Thompson is the PI. We thank Kenji Hakuta, Hsiaolin Hsieh, Lisa Zerkel, and Betsy Williams for their assistance during the MOOC itself and in assembling the data analyzed here.

Correspondence concerning this article should be directed to Sara Rutherford-Quach, Center for Education Research \& Innovation, SRI International, 333 Ravenswood Ave., BS367 | Menlo Park, CA 94025, sara.rutherford-quach@sri.com. 
Taking Away Excuses to Quit:

The Role of Supports in Completion and Learning in Online Professional Development for Teachers

\section{Endnotes}

${ }^{1}$ We focus here on completion of the three individual assignments for a variety of reasons. In part because participants completed the fourth course assignment collaboratively and there appears to be unreliable data about individuals' completion of this assignment in the de-identified data set we obtained from the platform provider. Two hundred fifty participants submitted the three individual assignments for the course, and 241 participants earned a Statement of Accomplishment (for which submitting the three individual assignments was a major component). Therefore, submission of these three assignments is a close proxy for full course completion.

2 Although quantitative data about final assignment completion was not reliable, as noted above, we analyzed the texts of participants' final assignment submissions to understand more about their cumulative learning from the course.

3 We use students to refer to K-12 students and participants to refer to individuals enrolled in the MOOC, who were the teachers of these K-12 students.

4 The transcript rating exercises were part of both the pre- and post-course surveys. These exercises addressed the second learning outcome for the course, which was to listen more carefully to student argumentation and use a specific tool to analyze argumentation samples. The exercises included a transcript of a conversation between two students in which the students were constructing an argument. We asked participants to rate the argument constructed by one of the students on three different dimensions: 1) the extent to which the student articulated a clear claim; 2) the extent to which the student provided support for the claim; and 3) the extent to which the student used language to convey relationships among ideas. These three dimensions were the basis for the Argumentation Analysis Tool (AAT) that participants were introduced to during the course. The AAT was developed by a multidisciplinary team, in consultation with national experts about argumentation in different content areas. Course modules formally introduced participants to the AAT; then as part of the course assignments, participants used it to rate samples of argumentation they collected from their own students. To measure how participants' argumentation analysis skills developed as a result of the course, the preand post-course survey asked participants to rate the same argumentation sample.

5 In supplementary analyses, for the two Likert-scale questions about learning outcomes that were asked on both the pre- and post-course survey, we also ran regression models testing the relationship between changes in participants' ratings over time and receiving supports. As with the main analyses presented in Table 5, in these supplementary analyses, there was no significant relationship between receiving supports and evidence of learning. Across eight models (four for each question, analogous to the four models for each question shown here, but with changes in ratings as the dependent variable), receiving supports never had a significant relationship to changes in participants' ratings of their knowledge about argumentation or their preparation for teaching argumentation. (Results available from the authors.) 


\section{References}

Adamopoulos, P. (2013). What makes a great MOOC? An interdisciplinary analysis of student retention in online courses. In International Conference on Information Systems (ICIS 2013): Reshaping society through information systems design (Vol. 5, pp. 4720-4740). Retrieved from http://aisel.aisnet.org/icis2013/proceedings/BreakthroughIdeas/13/

Allegretto, S. \& Michel, L. (2019). The teacher weekly wage penalty hit 21.4 percent in 2018, a record high: Trends in the teacher wage and compensation penalties through 2018. Economic Policy Institute and the Center on Wage \& Employment Dynamics at the University of Berkeley. Retrieved from: https://files.epi.org/pdf/161908.pdf

Askeroth, J. H., \& Richardson, J. C. (2019). Instructor perceptions of quality learning in MOOCs they teach. Online Learning Journal, 23(4).

Bernard, R. M., Borokhovski, E., Schmid, R. F., Tamim, R. M., \& Abrami, P. C. (2014). A metaanalysis of blended learning and technology use in higher education: From the general to the applied. Journal of Computing in Higher Education, 26(1), 87-122.

Bigsby, J. B., \& Firestone, W. A. (2017). Why teachers participate in professional development: Lessons from a schoolwide teacher study group. The New Educator, 13(1), 72-93.

Bill \& Melinda Gates Foundation. (2014). Teachers know best: Teachers' views on professional development. Bill \& Melinda Gates Foundation.

Clow, D. (2013, April). MOOCs and the funnel of participation. In Proceedings of the third international conference on learning analytics and knowledge (pp. 185-189).

Darling-Hammond, L., Hyler, M. \& Gardner, M. (2017). Effective teacher professional development. Palo Alto, CA: Learning Policy Institute.

Darkenwald, G. G., \& Valentine, T. (1985). Factor structure of deterrents to public participation in adult education. Adult Education Quarterly, 35(4), 177-193.

doi:10.1177/0001848185035004001

DeBoer, J., Ho, A. D., Stump, G. S., \& Breslow, L. (2014). Changing “course" Reconceptualizing educational variables for massive open online courses. Educational Researcher, 43(2), 74-84.

Dede, C., Jass Ketelhut, D., Whitehouse, P., Breit, L., \& McCloskey, E. M. (2009). A research agenda for online teacher professional development. Journal of Teacher Education, 60(1), 8-19.

EdSurge. (2014). How teachers are learning: Professional development remix. Retrieved from https://d3e7x39d4i7wbe.cloudfront.net/uploads/pdf/file/3/PD-Remix-EdSurge-Report2014.pdf 
Elliott, J. C. (2017). The evolution from traditional to online professional development: A review. Journal of Digital Learning in Teacher Education, 33(3), 114-125.

Evans, B. J., Baker, R. B., Dee, T. S. (2016). Persistence patterns in massive open online courses (MOOCs). Journal of Higher Education, 87, 206-242. doi:10.1353/jhe.2016.0006

Garip, G. Seneviratne, S.R. \& Iacovou, S. (2020). Learners' perceptions and experiences of study psychology online. Journal of Computers in Education, 7(4), 553-573.

Gašević, D., Dawson, S., Rogers, T., Gašević, D. (2016). Learning analytics should not promote one size fits all: The effects of instructional conditions in predicting academic success. Internet and Higher Education, 28, 68-84. doi:10.1016/j.iheduc.2015.10.002

Graham, C. R., Henrie, C. R., \& Gibbons, A. S. (2014). Developing models and theory for blended learning research. In A. G. Picciano, C. D. Dziuban, \& C. R. Graham, Blended learning: Research perspectives, 2 (13-33). New York: Routledge.

Halverson, L.R. \& Graham, C.R. (2019). Learner engagement in blended learning environments: A conceptual framework. Online Learning Journal, 23(2), 145-178.

Hargraves, A. (1992). Time and teachers' work: An analysis of the intensification thesis. Teachers College Record, 94(1), 87-108.

Ho, A. D., Reich, J., Nesterko, S., Seaton, D. T., Mullaney, T., Waldo, J., \& Chuang, I. (2014). HarvardX and MITx: The first year of open online courses. (HarvardX and MITX Working Paper No. 1)

Johnstone, J. W., \& Rivera, R. J. (1965). Volunteers for learning: A study of the educational pursuits of adults. Hawthorne, NY: Aldine.

Jona, K., \& Naidu, S. (2014). MOOCs: emerging research. Distance Education, 35(2), 141-144.

Jordan, K. (2015a). Massive open online course completion rates revisited: Assessment, length and attrition. International Review of Research in Open and Distributed Learning, 16, 341-358. Retrieved from http://www.irrodl.org/index.php/irrodl/article/view/2112

Joksimović, S., Poquet, O., Kovanović, V., Dowell, N., Mills, C., Gašević, D., ... \& Brooks, C. (2018). How do we model learning at scale? A systematic review of research on MOOCs. Review of Educational Research, 88(1), 43-86.

Karp, M. M. (2011). Toward a new understanding of non-academic student support: Four mechanisms encouraging positive student outcomes in the community college. CCRC Working Paper No. 28. Assessment of Evidence Series. New York: Community College Research Center, Columbia University. 
The Role of Supports in Completion and Learning in Online Professional Development for Teachers

Koller, D., Ng, A., Do, C., \& Chen, Z. (2013). Retention and intention in massive open online courses: In depth. Educause Review, 48(3), 62-63.

Kwakman, K. (2003). Factors affecting teachers' participation in professional learning activities. Teaching and Teacher Education, 19, 149-170.

Laurillard, D. (2016). The educational problem that MOOCs could solve: Professional development for teachers of disadvantaged students. Research in Learning Technology.

Lave, J., \& Wenger, E. (1991). Situated learning: Legitimate peripheral participation. New York: Cambridge University Press.

Lohman, M.C. (2005). A survey of factors influencing the engagement of two professional groups in informal workplace learning activities. Human Resource Development Quarterly, 16(4), 501-527.

Lohman, M.C. (2000). Environmental inhibitors to informal learning in the workplace: A case study of public-school teachers. Adult Education Quarterly, 50(2), 83-101.

Lohr, S. (2020, May 26). Remember the MOOCs: After near-death, they're booming. New York Times. Retrieved from https://www.nytimes.com/2020/05/26/technology/moocs-onlinelearning.html

Matzat, U. (2013). Do blended virtual learning communities enhance teachers' professional development more than purely virtual ones? A large-scale empirical comparison. Computers \& Education, 60(1), 40-51.

Means, B, Toyama, Y., Murphy, R. F., \& Baki, M. (2013). The effectiveness of online and blended learning: A meta-analysis of the empirical literature, Teachers College Record, $115(3), 1-47$.

Means, B., Toyama, Y., Murphy, R., Bakia, M. , \& Jones, K. (2010). Evaluation of evidencebased practices in online learning: A meta-analysis and review of online learning studies. Washington, D.C.: U.S. Department of Education, Office of Planning, Evaluation, and Policy Development.

Muilenburg \& Berge, Z.L. (2005). Student barriers to online learning: A factor analytic study. Distance Education, 26(1), 29-48.

Parsons, S. A., Hutchison, A. C., Hall, L. A., Parsons, A. W., Ives, S. T., \& Leggett, A. B. (2019). US teachers' perceptions of online professional development. Teaching and Teacher Education: An International Journal of Research and Studies, 82(1), 33-42.

Perna, L.W., Ruby, A., Boruch, R.F., Wang, N., Scull, J., Ahmad, S., Evans, C. (2014). Moving through MOOCs: Understanding the progression of users in Massive Open Online Courses. Educational Researcher, 43(9), 421-432. 
Pollard, H., Minor, M., \& Swanson, A. (2014). Instructor social presence within the community of inquiry framework and its impact on classroom community and the learning environment. Online Journal of Distance Learning Administration, 17(2).

Reich, J. (2015). Rebooting MOOC research. Science, 347(6217), 34-35. doi:10.1126/science. 1261627

Rutherford-Quach, S., Zerkel, L., \& Williams, E. (2015). Combining online and face-to-face learning: Examining a hybrid MOOC model for teacher professional learning. Paper presented at the meeting of American Educational Research Association, Chicago, IL.

Rutherford-Quach, S., Kuo, A. C., \& Hsieh, H. (2018). Understanding their language: Online professional development for teachers of ELLs. American Educator, 42(3), 27-31.

Scribner, J.P. (1999). Professional development: Untangling the influence of work context on teacher learning. Education Administration Quarterly, 35(2), 238-266.

Scrivener, S., Bloom, D., LeBlanc, A., Paxson, C., Rouse, C. E., \& Sommo, C. (2008). Opening doors, a good start: Two-year effects of a freshmen learning community program at Kingsborough Community College. New York: MDRC.

Stage, E. K., Asturias, H., Cheuk, T., Daro, P. A., \& Hampton, S. B. (2013). Opportunities and challenges in next generation standards. Science, 340 (6130), 276-277.

Trust, T., \& Horrocks, B. (2017). 'I never feel alone in my classroom': teacher professional growth within a blended community of practice. Professional Development in Education, 43(4), 645-665.

U.S. Department of Education, National Center for Educational Statistics. (2016). Percentage of public-school teachers based on years of teaching experience, average total years of teaching experience, percentage of teachers based on years teaching at current school, and average years teaching at current school, by selected school characteristics: 2015-16. Retrieved from https://nces.ed.gov/surveys/ntps/tables/ntps1516_18051504_tln.asp

U.S. Department of Education, National Center for Educational Statistics. (2012). Number of public-school teachers and percentage of public-school teachers who taught limitedEnglish proficiency (LEP) or English-language learner (ELL) students, by selected school and teacher characteristics: 2011-12. Retrieved from https://nces.ed.gov/surveys/sass/tables/sass 1112 _498_tn.asp

Vygotsky, L. S. (1978). Mind in society: The development of higher psychological processes (Cole, M., John-Steiner, V., Scribner, S. \& Souberman, E., Eds.) Cambridge, MA: Harvard University Press. 
The Role of Supports in Completion and Learning in Online Professional Development for Teachers

Wang, Y. \& Baker, R. (2015). Content or platform: Why do students complete MOOCs? Journal of Online Learning and Teaching, 11(1), 17-30.

Wang, C.H., Shannon, D.M. \& Ross, M.E. (2013). Students characteristics, self-regulated learning, technology self-efficacy, and course outcomes in online learning. Distance Education, 34(3), 302-323.

Wei, R. C., Darling-Hammond, L., Andree, A., Richardson, N., Orphanos, S. (2009). Professional learning in the learning profession: A status report on teacher development in the United States and abroad. Dallas, TX: National Staff Development Council.

Wenger, E. (1998). Communities of practice: Learning, meaning, and identity. Cambridge: Cambridge University Press.

Yurkofsky, M. M., Blum-Smith, S., \& Brennan, K. (2019). Expanding outcomes: Exploring varied conceptions of teacher learning in an online professional development experience. Teaching and Teacher Education, 82(1), 1-13. 